\title{
COMMON ORIGIN OF THE SECOND AND THIRD PALMAR DIGITAL ARTERIES IN AN ULNAR TYPE SUPERFICIAL PALMAR ARCH: A CASE REPORT
}

\author{
Eleni PANAGOULI ${ }^{1}$, Gregory TSOUCALAS ${ }^{\circledR}{ }^{\circledR}$, Aliki FISKA ${ }^{2}$, Dionysios VENIERATOS ${ }^{1}$, \\ Panagiotis SKANDALAKIS ${ }^{1}$
}

${ }^{1}$ Department of Anatomy, Medical School, National and Kapodistrian University of Athens, Greece

${ }^{2}$ Department of Anatomy, School of Medicine, Democritus University of Thrace, Alexandroupolis, Greece Received 19 Sept 2018, Accepted 24 Nov 2018 https://doi.org/10.31688/ABMU.2018.53.4.23

\begin{abstract}
The superficial palmar arch (SPA) is usually formed by an anastomosis between the ulnar artery (UA) and the radial artery (RA) and gives off three common palmar digital arteries. Many variations of the SPA have been reported in the pertinent literature (ulnar type arch, radial type arch, complete and incomplete arch, etc). Complete SPA is reported to be formed in the $69.2 \%$ of the right hands and $70.5 \%$ of the left hands in the pertinent literature. We report a case of a complete ulnar type SPA, where the first and second palmar digital arteries emerge from a common stem.
\end{abstract}

Keywords: superficial palmar arch, ulnar artery, radial artery, cadaver.

\section{Résumé}

Origine commune de la deuxième et la troisième artères digitales dans un arc palmaire superficiel de type ulnaire - présentation de cas

L'arcade palmaire superficielle (APS) est généralement formée par une anastomose entre l'artère ulnaire et l'artère radiale en résultant trois artères digitales palmaires communes. De nombreuses variations de la APS ont été rapportées dans la littérature de spécialité (arc de type cubital, arc de type radial, arc complet et incomplet, etc.). La APS complète serait formée dans $69,2 \%$ des mains droites et 70,5\% des mains gauches dans la littérature de spécialité. Dans la présente étude, nous rapportons un cas de APS de type ulnaire complet, où les première et seconde artères digitales palmaires émergent d'une tige commune.

Mots-clés: arcade palmaire superficielle, artère ulnaire, artère radiale, cadavre. 


\section{INTRODUCTION}

The superficial palmar arch (SPA) is an anastomosis between the ulnar artery (UA, which is the main supplying vessel) and the radial artery (RA, in which the arch terminates) and gives off the three common palmar digital arteries. The SPA is covered by palmaris brevis and the palmar aponeurosis and it is superficial to flexor digiti minimi, branches of the median and ulnar nerves, the tendons of the flexor digitorum muscles (superficialis and profundus) as well as the lumbrical muscles. In 20\% of the cases, four common palmar digital arteries (one for each web space) may rise from the superficial branch of the UA ${ }^{1}$.

In the present study, we report a case of a complete SPA, being formed by the UA only, where the first and second palmar digital arteries emerge from a common stem.

\section{Case report}

The reported anatomical variations were discovered in the upper extremities of a male Caucasian cadaver, during routine educational dissection at the Anatomy Department of the Medical School of the University of Athens, Greece. The cadaver derived from body donation with informed consent, written and signed (with signature authentication) by the donor himself. The anatomy of the branches of the UA and RA and the arterial pattern of the palmar arches were carefully examined in each arm. During this procedure, we discovered an abnormal pattern of the SPA in the right hand.

The UA at the level of the wrist, passed over the flexor retinaculum and entered the palm, with the ulnar nerve, where it created the superficial palmar arch, which gave off three common palmar digital arteries (Figure 1). The first one was an aberrant one and supplied the index and thumb, normally irrigated by the radial artery itself or the deep palmar arch. The second one gave a common stem which after a short course divided in two branches which substituted the first and second digital arteries for second and third web space (Figure 1). Then the SPA continued its course and gave rise to the third palmar digital artery (for the third and fourth web space) and finally to the palmar digital artery for the medial side of the little finger (Figure 1). The SPA was formed only by the UA and was complete as a fairly wide branch continued towards the thumb and one towards the little finger. The RA did not participate at the formation of the SPA. The deep palmar arch presented no variations, as well as the palmar digital nerves. The arterial pattern at the left arm was the expected one.

\section{Discussion}

Normally, three common palmar digital arteries arise from the convexity of the SPA and divide into two proper palmar digital arteries which anastomose with the dorsal digital arteries. Palmar digital arteries constitute the main supply of the fingers, because the dorsal digital arteries are much smaller. The origins of the palmar digital arteries of the thumb are quite variable, as they might emerge from a single „princeps pollicis" (branch of radial artery), or separately from the superficial palmar arch ${ }^{1}$.

SPA may present a large number of abnormalities and some of them might put at risk the blood flow $^{2}$. According to the classical anatomical text books a third of the superficial palmar arches are formed by the UA alone (ulnar type SPA), a third by both UA and RA (radio - ulnar type SPA), and a third by the arteria radialis indicis, a branch of either arteria princeps pollicis or the median artery (radian-ulnar-median type SPA) ${ }^{1}$. Complete arch (clear anastomosis between the arteries forming it) with three or four common palmar digital arteries is reported to be formed in the $69.2 \%$ of the right hands and $70.5 \%$ of the left hands in the pertinent literature $^{3}$. According to a recent meta-analysis manuscript by Zarzecki et al in $2018^{4}$, complete arch is reported in the $75.7 \%$ of the cases and incomplete (no anastomosis between the arteries forming the arch or the UA failed to supply the ulnar side of thumb and radial side of the index finger) in the $24.3 \%$. The palmar digital arteries might all be branches of the UA in the $37 \%$ of the cases, with the first one being branch of the radial artery in $13 \%{ }^{2}$. Rarely, the palmar digital arteries might emerge independently from the RA, UA or the median artery (1-4\%) without forming an arch. SPA might be double in $0.7 \%$ of the cases ${ }^{4}$.

In our case, the SPA was complete and ulnar type (with the participation of UA only). Three palmar digital arteries emerged, with the third one arising directly from the superficial palmar arch, while the first and second ones arose from a short common stem. As the most of the studies examine the superficial palmar arch as a whole ${ }^{3.5}$, there are not sufficient data about the variations of the palmar digital arteries.

\section{Conclusions}

As the injury of common palmar digital nerves and arteries is at high risk during surgical procedures in the hand (neuro-suture, arterial repairs, replantation of severed limbs etc), the knowledge of the variations of these structures is important. Furthermore, 


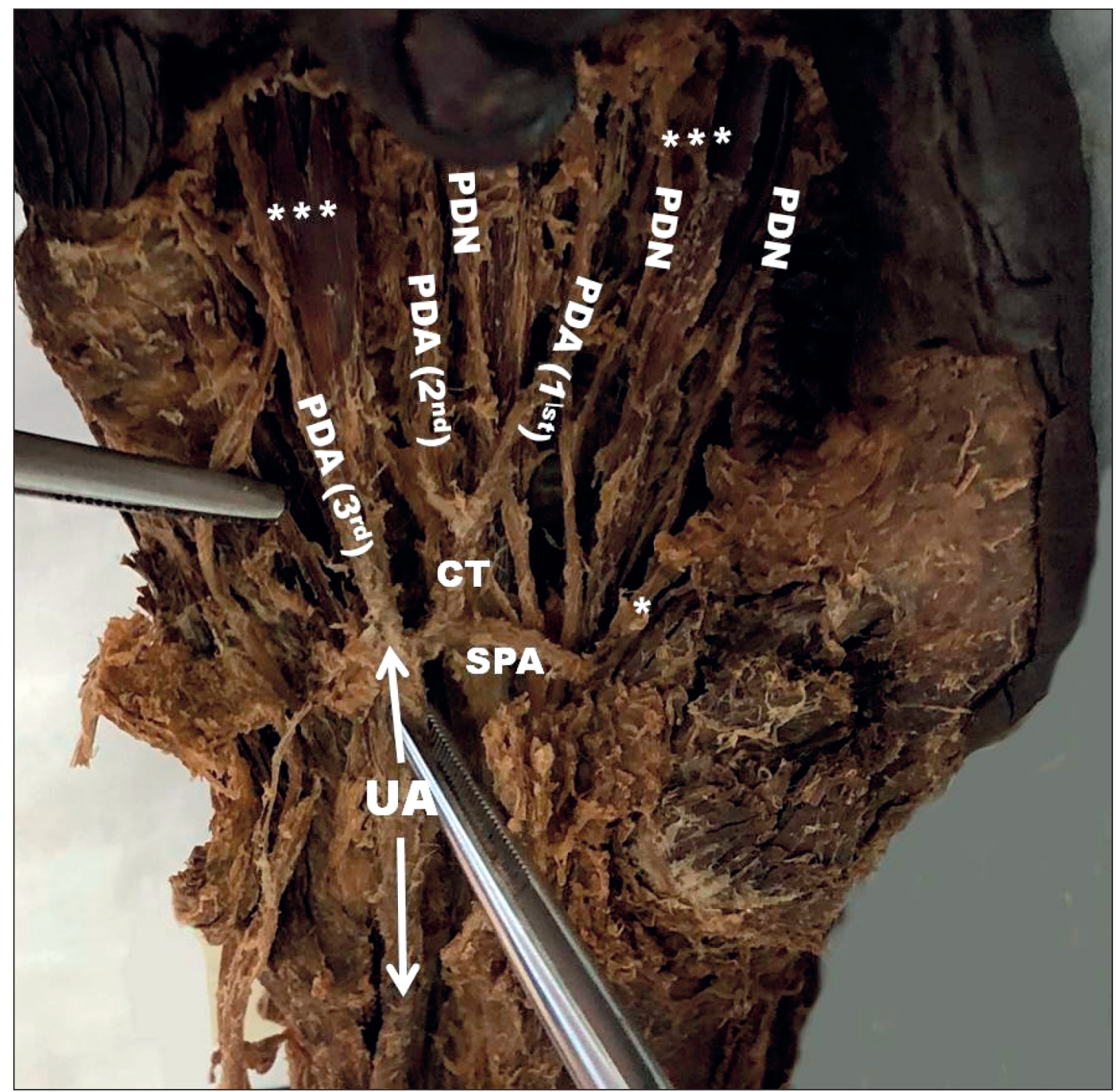

Figure 1. Ulnar type superficial palmar arch (SPA), where the first and second palmar digital arteries (PDA) emerge from a common stem (CT). UA: ulnar artery, PDN: palmar digital nerve, *: branch for the index and thumb, **: branch for the medial side of the little finger, ***: tendons of the superficialis flexor digitorum muscle.

anatomical variations in the palm area may be the cause of nerve entrapment syndrome or ischemia 5 .

\section{Compliance with Ethics Requirements:}

„The authors declare no conflict of interest regarding this article"

„The authors declare that all the procedures and experiments of this study respect the ethical standards in the Helsinki Declaration of 1975, as revised in 2008(5), as well as the national law. Informed consent was obtained from the patient included in the study"

"No funding for this study"

\section{References}

1. Standring S, Borley NR, Collins P, et al (eds.): Gray's anatomy. The anatomical basis of clinical practice. Elsevier, Edinburgh, 2008.

2. Lippert H, Pabst R. Arterial variations in man. Classification and Frequency. Bergmann, Muenchen, 1985.

3. Kaplanoglu H, Beton O. Evaluation of anatomy and variations of superficial palmar arch and upper extremity arteries with CT angiography. Surg Radiol Anat 2017;39(4):419-426.

4. Zarzecki MP, Popieluszko P, Zayachkowski A, Pękala PA, Henry BM, Tomaszewski KA. The surgical anatomy of the superficial and deep palmar arches: a meta-analysis. J Plast Reconstr Aesthet Surg 2018;71(11):1577-1592.

5. Dong T, Maoyong Fu. Anatomic variation of the common palmar digital nerves and arteries. J Korean Neurosurg Soc 2015;57(3):219-220. 